\title{
Visualizing time: how linguistic metaphors are incorporated into displaying instruments in the process of interpreting time-varying signals
}

\section{Germà Garcia-Belmonte}

Keywords visualization · conceptual metaphor $\cdot$ instrument-mediation · time-varying signal

\begin{abstract}
Spatial visualization is a well-established topic of education research that has allowed improving science and engineering students' skills on spatial relations. Connections have been established between visualization as a comprehension tool and instruction in several scientific fields. Learning about dynamic processes mainly relies upon static spatial representations or images. Visualization of time is inherently problematic because time can be conceptualized in terms of two opposite conceptual metaphors based on spatial relations as inferred from conventional linguistic patterns. The situation is particularly demanding when time-varying signals are recorded using displaying electronic instruments, and the image should be properly interpreted.
\end{abstract}

This work deals with the interplay between linguistic metaphors, visual thinking and scientific instrument mediation in the process of interpreting time-varying signals displayed by electronic instruments. The analysis draws on a simplified version of a communication system as example of practical signal recording and image visualization in a physics and engineering laboratory experience. Instrumentation delivers meaningful signal representations because it is designed to incorporate a specific and culturally favored time view. It is suggested that difficulties in interpreting time-varying signals are linked with the existing dual perception of conflicting time metaphors. The activation of specific space-time conceptual mapping might allow for a proper signal interpretation. Instruments play then a central role as visualization mediators by yielding an image that matches specific perception abilities and practical purposes.

Here I have identified two ways of understanding time as used in different trajectories through which students are located. Interestingly specific displaying instruments belonging to different cultural traditions incorporate contrasting time views. One of them sees time in terms of a dynamic metaphor consisting of a static observer looking at passing events. This is a general and widespread practice common in the contemporary mass culture, which lies behind the process of making sense to moving images usually visualized by means of movie shots. In 
contrast scientific culture favored another way of time conceptualization (static time metaphor) that historically fostered the construction of graphs and the incorporation of timedependent functions as represented on the Cartesian plane into displaying instruments. Both types of cultures, scientific and mass, are considered highly technological in the sense that complex instruments, apparatus or machines participate in their visual practices.

\section{Germà Garcia-Belmonte}

Universitat Jaume I, Department of Physics, ES 12071 Castelló, Spain

e-mail: garciag@fca.uji.es

\section{Published: Cultural Studies of Science Education (2016) DOI: 10.1007/s11422-015-9686-4}

La visualització espacial és un tema d'investigació educativa ben establert que ha permès millorar les habilitats dels estudiants de ciència i d'enginyeria pel que fa a les relacions espacials. En diversos camps científics hi ha una connexió directa entre la visualització com una eina de comprensió i la instrucció. L'aprenentatge de processos dinàmics es basa principalment en representacions o imatges espacials de caràcter estàtic. Tanmateix, la visualització del temps és inherentment problemàtica perquè el temps pot ser conceptualitzat en relació amb dues metàfores conceptuals oposades que es basen en relacions espacials, tal com s'infereix de patrons lingüístics convencionals. La situació és particularment exigent quan senyals variables amb el temps es registren utilitzant els instruments electrònics, i la imatge ha de ser interpretada correctament.

Aquest treball tracta sobre la interacció entre les metàfores lingüístiques, el pensament visual i la mediació d'instruments científics en el procés d'interpretació de senyals variables amb el temps que es registren amb aparells electrònics. L'anàlisi es basa en una versió simplificada d'un sistema de comunicació com a exemple pràctic d'enregistrament del senyal i la visualització d'imatges en una classe experimental de laboratori de física i d'enginyeria. La instrumentació ofereix representacions del senyal significatives perquè és dissenyada per incorporar una visió específica i culturalment afavorida del concepte de temps. Es suggereix que les dificultats en la interpretació dels senyals variables amb el temps estan vinculades amb la doble percepció conflictiva que existeix de metàfores temporals. L'activació d'un mapatge específic de la relació espai-temps permet una interpretació correcta del senyal. Els instruments juguen llavors un paper central en la visualització com a mediadors, en 
proporcionar una imatge que connecta capacitats humanes de percepció específiques i propòsits pràctics.

A partir d'anàlisis antropològiques i linguiístiques s'identifiquen dues formes d'entendre el temps, amb característiques bé estàtiques bé dinàmiques, que s'utilitzen en diferents situacions i pràctiques dels estudiants. S'observa que hi ha instruments de visualització específics pertanyents a diferents tradicions culturals i que incorporen punts de vista oposats del temps. Un d'ells veu el temps a través d'una metàfora dinàmica que consisteix en un observador estàtic mirant passar els esdeveniments. Aquesta visió és una pràctica generalitzada, comuna en la cultura de masses contemporània, que es troba darrere del procés de donar sentit a les imatges en moviment produïdes per la successió de fotogrames en les pel-lícules. Per contra la cultura científica va afavorir una altra forma de conceptualització de temps (amb una metàfora estàtica) que històricament va fomentar la construcció de gràfics i la incorporació en instruments electrònics de funcions dependents del temps representades en el pla cartesià. Tots dos tipus de cultures, científica i de masses, es consideren altament tecnològiques en el sentit que instruments complexos, aparells o màquines participen en les seues pràctiques visuals. 
In recent years there has been much interest in determining the role of visualization in science and technology instruction and how it improves students' technical reasoning (Gilbert 2007b; Gilbert et al. 2008). Visualization is understood either in terms of physical objects as pictures, illustrations, schematic diagrams, and drawings commonly used in instruction (Phillips et al. 2010), or as mental images visualized by the students' mind. The previous twofold meaning is interconnected by the cognitive activity that maps objects and mental images (Gilbert 2007a), and highlights the interplay between internal models and external structures (Rapp and Kurby 2008). These studies revealed that visualization lies behind creative reasoning and thinking, and allows for a productive interpretation, manipulation, and transformation of spatial perceptions by the mind. It is recognized that students more easily engage in the construction of mental models of particular scientific issues through visualizations. The increasing, widespread use of computer-generated interactive images facilitates rapid hypothesis testing, development of inferences, and prospective checking (Rapp 2007). It is obvious that visualization highlights space as a central component, and in consequence refining perception skills of spatial relations was identified as a primary concern of technical training (Contero et al. 2005). In the particular case of mathematical thinking, visual perception has been regarded as a central component of reasoning processes, not only for the obvious case of geometry but even for arithmetic and calculus. Education research projects on mathematics are particularly interesting because they emphasize shape perception as a reliable mechanism capable of capturing proper knowledge (Giaquinto 2007). Also learning of chemistry topics is recognized to be enhanced by using interactive planar 3D molecular models which allow students to easily build mental representations (Wu and Shah 2004).

As teachers of physics and engineering, we largely rely upon visual presentations of subject matter concepts during the instruction. Students usually show good responses when they are encouraged to use visual thinking for basic analysis of mathematical functions in addition to 
formal calculations. However, there are occasions in which the instruction seems more demanding: particularly those in which dynamic concepts such as movement, displacement or time are discussed. Establishing the proper way to convey information about evolution or progress in scientific structures and models is not a simple task. Some authors pointed out that the congruent choice of using animated schemas or diagrams (as in a movie) does not produce the expected successful learning outcomes (Tversky et al. 2002). That study concluded that progress or change is better understood relaying upon static, or a sequence of static, pictures, rather than by looking at a representation of the moving phenomenon. However, other educators asserted that a dynamic representation of a dynamic phenomenon is more authentic and should increase student comprehension and conceptual understanding (McKagan et al. 2008). By contrast it has been recognized that the mere use of dynamical visualizations does not assure fruitful learning (Lowe and Schnotz 2007). In some cases the students' cognitive capacities become overload by the continuous changes in the visual display (Bell et al. 2012). Experienced teachers know about the advantages and disadvantages of a given visuallydynamic education tool based on computer simulations.

Time as a concept is involved in almost every science lecture. In many practical situations (in laboratory undergraduate introductory courses for instance) students elaborate on images related to dynamic processes making use of recording instruments, that is any kind of apparatus incorporating a data acquisition system. Recording instruments were developed to provide still images of changing signals, in good accordance with Barbara Tversky's experimental evidence that static pictures better activate reasoning and interpretation (Tversky et al. 2002). As we will see latter the static characteristic of the displayed images is linked with a key feature of any scientific instrument: the faculty of making measurements. We refine here our definition by naming 'displaying electronic instruments' a special case of recording instruments able to provide graphs as readable outcomes. These graphs belong to the kind of 
representations commonly used in the scientific texts (the representation of two variables on a Cartesian plane), and form the basis for the implementation of measurements (Roth et al. 2005). Our work asserts that displaying instruments were designed to embody perceptual human requirements in order to visually facilitate the interpretation of dynamic processes for measuring purposes. We elaborate here on an example of this general statement by confronting conventional ideas about time with the visualization and interpretation of simple time-varying signals when displaying electronic instrumentation is used.

Although the general term visualization can be understood diversely, I want to emphasize here the way physical drawings and images connect to mental views. In the simplest cases the spatial structure of the image can be rather straightforwardly interpreted, but in many other important situations images are produced or built by instruments devoted to specific purposes. Here visualization is a process in which several actors intervene. There is obviously the observer and her/his abilities and skills, but also de instrument that delivers the image. Clearly the displaying instrument not only builds images, it is effectively constructed by engineers and designers that select what the instrument should show and should hide. In addition all these actors work within specific cultural traditions following particular practices. So that I am of the opinion that visualization, particularly its manifestation in a technological environment, is always a culturally-driven, multifaceted process oriented and mediated by instruments.

\section{Displaying instruments embody visual traditions and linguistic metaphors}

Dual coding theory (Clark and Paivio 1991) assumes that there are two cognitive subsystems, one specialized for the representation and processing of nonverbal objects, and the other specialized for dealing with language. In some cases both subsystems activate mutually in such a way that the combination of linguistic information and visual information provides dual support for learning and knowledge acquisition. Such dual activation is obvious in the specific 
case of pure spatial relations: a certain size naturally matches a visual segment. But it is known that common reasoning is highly metaphorical and this allows for mapping separate concept domains such as time and space (Lakoff and Johnson 1980). Therefore in the verbal side, time is mainly conceived in natural languages using spatial terms (Boroditsky 2000). This is also the case in the visual side. As known one can easily interpret time plots relying on a spatial metaphor, in which time corresponds to the independent variable of the Cartesian plane. Thanks to these space-time metaphors one is able to 'see' time as if it were a spatial dimension. As next explained we will use linguistic approaches as a gate through which introduce students into the existing dual and conflicting conceptualization of time. This duality expresses itself in the mental imagination allowing for the interpretation of visual displays.

When instruments for signal recording are called into scene during a laboratory practice, usual perception often fails in interpreting drawn signals. We suggest that some sort of perceptual recognition needs to be built prior to proper signal interpretation. This visualization refinement might be achieved by activating specific space-time metaphors (Lakoff and Johnson 1999). As we shall attempt to show, the construction of such as refinement in the visualization of instrumentation-mediated time-varying signals also relies upon conventional, although less straightforward, time ideas. Because time in science is a ground-level magnitude in the definition of every system and is involved in basic approaches, it would be interesting to explore how time is used in everyday talk and in terms of what ideas are conceived in ordinary language (Boroditsky 2000).

We elaborate later on the relationship between outside and inside (with respect to the education institution) knowledge environments. Here it is proposed that specific linguistic time metaphors are incorporated into particular displaying instruments. Whereas scientific instrumentation usually delivers static images in accordance with their superior capacity for reasoning activation and measuring, other representation instruments such as those devised to 
display movies in modern cinema largely relies upon dynamic images. As we later see specific cultural traditions favor then particular time views. In any case, it should be recognized that time is evidently an elusive concept as anthropological studies had pointed out (Munn 1992). Anthropology revealed in many works how time and space are intimately intricate dimensions that cannot be disentangled (see for instance (Granet 1968)). Considering this general statement we will follow here the metaphorical mapping proposed by George Lakoff and Mark Johnson that allows conceiving time in terms of spatial relations.

A laboratory instructional situation makes up the framework for this study. Students usually have trouble in understanding what occurs when they switch on a common laboratory instrument: the oscilloscope (Dias Pereira 2006) and a signal appears on the screen. The oscilloscope is a general-purpose electrical instrument devised to record in a simple way the time-evolution of signals. In connection to sensors which converts physical magnitudes into time-varying voltages, oscilloscopes are absolutely necessary to observe the change of any physical phenomenon. This explains why one can find them in any educational laboratory of physics and engineering. The instrument is provided with a screen on which a voltage (signal) is displayed as a function of time (Fig. 1). The signal representation on the instrument screen forms a sort of Cartesian plane $(x-y$ plane $)$. Oscilloscopes belong to a wide family of instruments and apparatus of common use in electronics. Most of these instruments (frequency analyzers, impedance meters, and network analyzers) deliver a processed outcome that largely departs from the original signal captured by the acquisition system. On the contrary oscilloscopes are used to display time-varying signals introducing as minor as possible modifications into the signal shape. The oscilloscope intends to provide a representational replica of a dynamic variable. Apart from oscilloscopes constructed for professional purposes, there exist education and training versions specially designed for engineering and physics laboratory courses. In any case the basic working principles are shared by professional and 
training versions (Dias Pereira 2006).

It should be noted that learning about the use of oscilloscopes is largely a practical task. The proper way of understanding how oscilloscopes really function is by comparing displayed images with a variety of known input signals in different situations. More importantly, confronting outcomes of instruments controlled by different students during instruction allows them to gain a collective sense on what the equipment is able to do and its main limitations. As occurring with visual learning in other situations, it is only by hand-on practice that visual recognition and interpretation is built in a rich and diverse instructional environment that gathers a variety of phenomena and mechanisms.

In education research the identification of instructional situations in which students show difficulties in understanding (not only subject matter concepts but also practical procedures) might reveal ground level difficulties. Accordingly, a very general system concept widely used in teaching science and engineering (electronics, data communication, and signal transmission) at an introductory level will be here used as example. A basic "communication system" comprises two units, namely emitter and receiver, which are connected by means of a channel that transmits some kind of signal. The notion of transmission obviously involves the concept of time. The analysis of how time is conceived and used in a practical realization of a communication system will serve as describing example of the mechanisms involved in perceptual recognition of simple shapes, mediated by a recording instrument.

The oscilloscope practice has been selected because it allows drawing upon a simple, but non-trivial, visualization situation. The practical situation permits exploring into the interplay existing between conventional language, visualization and instrumental mediation, in order to gain new insight into the mechanisms underlying visual understanding. Findings derived from linguistic analyses are next briefly summarized insofar as conventional conceptualizations about time are concerned. Afterwards, the instructional utility of the linguistic perspective is 
explained by recalling the problems students often experience in interpreting images drawn by the oscilloscope. Finally a sequence in the activation of time-space metaphors is suggested that allows decomposing the instrument operation and the consequent building of a readable timevarying signal image.

\section{The oscilloscope: an example of displaying instrument}

Let us imagine a laboratory class which explains to students how the oscilloscope functions. Oscilloscopes are rather sophisticated apparatus commonly introduced to undergraduate students in science and engineering training laboratories during the first degree course. Students rarely have previous experience with oscilloscopes, although rapidly observe that the instrument is equipped with a screen for representation of signals. Obviously physics and engineering textbooks are provided with explanations about what a signal is and the methods to capture time-varying quantities. This previous (out-of-lab) training focuses on rather formal and mathematical aspects of the subject matter in such a way that a 'signal' is conceptually reduced to a mathematical function which has a univocal representation on the Cartesian plane. Time is always the horizontal line corresponding to the $x$-axis. There is then a wide gap between what students expect to see (a stable trace on a sort of $x-y$ plane) and the image displayed by the oscilloscope. During laboratory instruction they are informed on the experimental set-up made up of several instruments. Students are encouraged to work with a set of function generators (emitter) and oscilloscopes (receiver), and with cables to connect both types of apparatus. Let us assume for instance a sinewave of a certain frequency selected on the function generator front panel. After the connection, students may feel astonished by observing the variety of images appearing on the screens of different oscilloscopes, as those shown in Fig. 1. This diversity alerts students that there is not a direct, simple and easy relation between the input signal and the output image. 
Oscilloscopes are a type of instruments devised to convert changing magnitudes (called in electronics time-varying signals) into a stable and stopped image with time congealed in the $x$ axis of the Cartesian plane. This transformation is not straightforward and it seems to be the key contribution from the original designers of the instrument. My point here was trying to explain this dynamic-to-static movement to first year undergraduate student without any knowledge of electronics. At the beginning of the laboratory class students, which have not previously worked with oscilloscopes, are regarded as instrument users. For them the oscilloscope is no more than a black box. How to gain intuition about the internal oscilloscope transformations without the necessity of opening the box was a real challenge to me as laboratory teacher.
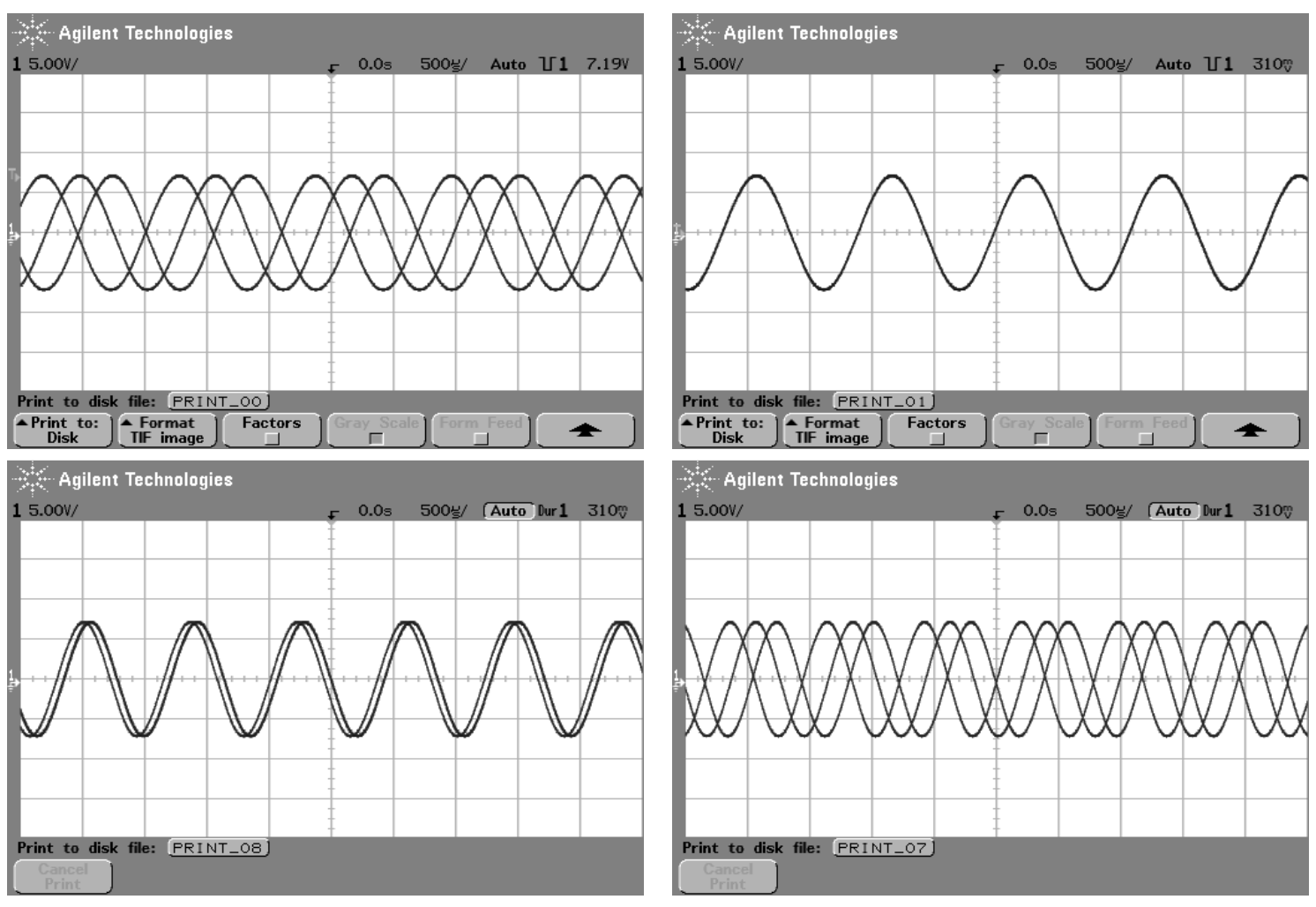

Figure 1. Some images on the oscilloscope screen corresponding to a sinewave coming from a function generator. Vertical axis corresponds to the input voltage while horizontal axis is directly assimilated to time. 
Students are usually able to understand that the signal comes from the function generator, reaches the oscilloscope and then the apparatus displays a related picture. In their first approximation to the instrument they have enough time to work and play with the connections and change some apparatus settings (time and voltage scales, input channel, trigger mode...). As occurring with other kinds of practical learning the interaction between the student and the instrument, and among students in relation to the instruments too, is necessary to progress into the apparatus understanding and recognition of eventual limitations. As observed in Fig. 1, students obtain different images depending on the particular oscilloscope trigger configuration. How can the same function generate such a set of different images? The real observation of the signals is often more interesting because under some oscilloscope configurations, waves seem to be actually "passing" from one side of the screen to the other before the students' very eyes. The fact of observing a signal passing activates internal modes of perceiving time in a dynamic way. The oscilloscope screen features then other displaying technologies students are more used to watch. Film screens or TV sets are devised to reproduce changing images in accordance with the evolving nature of the signals. The conflict becomes apparent because students try to seek stable (frozen) images as those appearing in their textbooks that are surprisingly only present in some oscilloscopes, while simultaneously dynamic outcomes are also visible on other screens. As pointed out previously, dynamic images do not fulfill the requirement of stillness necessary for measuring purposes.

Students intuitively sense that the answer to the image multiplicity deals with the trigger keys on the front panel of the oscilloscope, but they are usually unable to give a suitable explanation for the variety observed in the apparatus responses. Experts know that it is simply an issue concerning the synchronization between the incoming signal and the time-base of the oscilloscope which allows acquiring a set of images exactly at the same oscillation instant. 
The superposition of different acquisitions starting at the same oscillation point yields the apparent illusion of observing a fully stopped signal that is in reality time-varying. The synchronization process implies a sort of apparatus adjustment or tuning that it is fully automatic in the oscilloscope digital versions, and consequently becomes hidden for the students. We believe that the problem for students is even more severe because conventional concepts about time need to be activated in the correct ordering. It is next explained that there is a duality within the intuitive views about time evolution related to its dynamic and static features, and how students might need a guide to achieve successful understanding.

\section{Conventional Conceptualizations of Time}

Time in common language is not conceptualized in its own terms. Instead people talk about time in conventional conversations by relying on a spatial analogy. Lakoff and Johnson expressed this by indicating that "Spatial orientations like up-down, front-back, on-off, centerperiphery, and near-far provide an extraordinarily rich basis for understanding concepts in orientational terms." Time is no more than a specific instance (Lakoff and Johnson 1980). They used the more linguistic term "metaphor" to name these analogies. Three different metaphors by which we express time-related sentences were identified, which are claimed as being common in English and in most languages usage.

These three "spatial time" views are briefly outlined here. "The most basic metaphor for time involves an observer at the present who is facing toward the future with the past behind the observer. We will refer to this as the Time Orientation metaphor." (Lakoff and Johnson 1999) This analogy lies behind common sentences like: “That's all behind us now. Let's put that in back of us. He has a great future in front of him." Nevertheless, recent studies have evidenced that this is not a universal pattern embracing different linguistic groups (Boroditsky 2001), and that a substantial flexibility in conceptual projections exists when different 
individuals, specific tasks, and cultures are compared (Torralbo et al. 2006). For some linguistic groups future is instead situated behind the speaker (Núñez and Sweetser 2006). Lera Boroditsky and co-workers (Fuhrman et al. 2011) pointed out that Chinese speakers conceptualize time in terms of the vertical direction in opposition to horizontal orientation common in Western languages.

The basic time conceptualization in spatial frames of reference is completed in two different ways in English (Boroditsky 2000) and, based on my own experience, also in Latin (Catalan and Spanish) languages. The second metaphor sees the observer at a stationary position "facing in a fixed direction." and "There is an indefinitely long sequence of objects moving past the observer from front to back. The moving objects are conceptualized as having fronts in their direction of motion." Replacing "objects" by time, and "the motion of objects" by the passage of time completes the analogy. This is the essence of the Moving Time metaphor as we can see with the following sentences: "The time will come when there are no more typewriters. The deadline is approaching. The time to start thinking about irreversible environmental decay is here. The time for the end-of-summer sales has passed." Figure 2 tries to capture the essence of this analogy with the particularity of seeing time passing from left to right instead of from front to back as inferred from the strict Moving Time metaphor. 


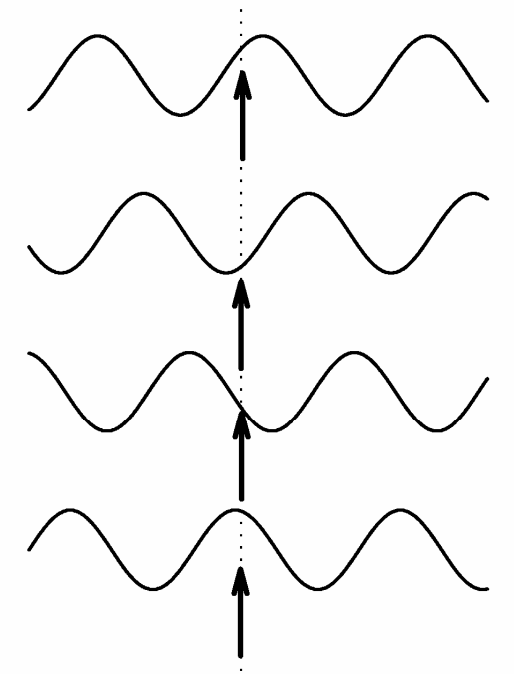

Figure 2. Sketch of the Moving Time analogy: the time-dependent function passes from right to left over the fixed location of the observer (arrow). In this image time evolves from top to bottom.

The third way to conceptualize time is called the Moving Observer, or Time's Landscape. Here each location in the observer's path is a time so that the observer is moving, where the present is the current observer's location. Again there are examples of this analogy in contemporary English: "What will be the length of his visit? Let's spread the conference over two weeks. We're coming up on Christmas. I'll be there in a minute." (Lakoff and Johnson 1999) As sketched in Fig. 3, the arrow, which now stands for the observer, is moving along the time axis as if a stable landscape exists. Again front-to-back observer orientation is replaced by left-to-right direction. 


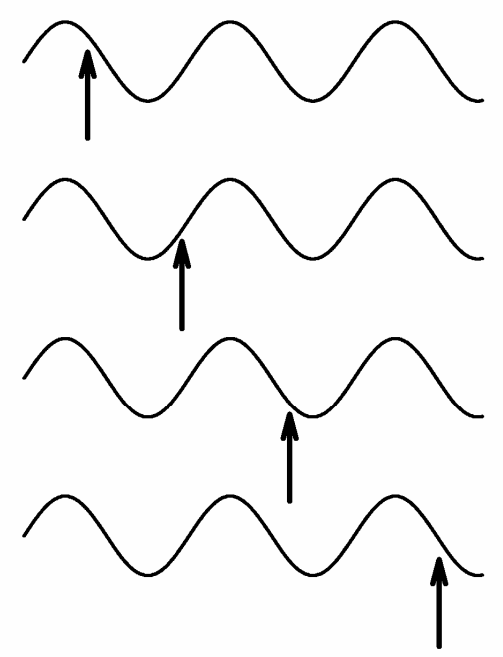

Figure 3. Sketch of the Moving Observer or Time Landscape analogy: the time-dependent function forms a fixed background in which the observer (arrow) moves from right to left.

Space and time are only one example of a large set of domain pairs systematically mapped in ordinary language. The question of whether such domain-mapping is actually real or simply results from a set of local polysemies was experimentally addressed. According to these studies (Gentner et al. 2002), large-scale systems of conventional conceptual metaphors can be seen then as psychologically real conceptual systems. Strictly speaking the Lakoff and Johnson metaphorical space-time mapping relies on a highly specific type of embodiment, that that regards the human body as a reference framework. Therefore its application or extension to displaying instruments does not seem evident at first glance. But this is precisely my intention: to make clear that instruments also incorporate these metaphors. Instrument makers introduced specific time views into the equipment design process to promote particular visualization. Consequently these tacit ideas might improve student comprehension when become explicit.

It should be noted that the Lakoff and Johnson's approach on time conceptions has many 
points in common with previous philosophical and anthropological accounts (Gell 1992). Roughly speaking the outlined linguistic approach basically distinguishes the practical use of two ways of talking about time of static and dynamic features. Moreover, these "two metaphors are, strictly speaking, inconsistent with each other ... But these are actually minimally differing variants of one another. In short, they are figure-ground reversals of one another. ... We will refer to such metaphor as duals and the phenomenon as duality." (Lakoff and Johnson 1999) This duality reveals embodied modes of visualization: either the observer is moving and sees a stable background or there is a changing background observed by a still eye. Hence time is essentially conceived either in a dynamic or static way, and both options are mutually exclusive. It should be recognized that the twofold spatial view of time was previously recognized by early XXth century idealist philosophers as J. M. E. McTaggart (Gale 1968, 1967). Even contemporary philosophical theories about time situate it between two polarized extremes usually called the A- and B-series. We highlight here the main contrasting features of each philosophical theory particularly in relation to the Lakoff and Johnson's approach. A-series sees time in a dynamic manner with 'passage' and 'becoming' as basic conceptualizations. Alfred Gell graphically quoted that A-series conceives "time as a wafer-thin screen of unique events in a continuously changing and moving present" (Gell 1992). In contrast the B-series highlights the static character of time with 'being' and Cartesian representation as useful ideas. Time is then understood as a congealed concept, "more or less coextensive with space". Although philosophical and linguistic approaches differ in many aspects that would need further clarification, it is clear that A-series and Moving Time views gather the basic background of the dynamic features of time. In the opposite extreme, B-series and Time Landscape analogy has in common the static view by means of which time is understood.

The Time's Landscape analogy is particularly important when we deal with drawing time- 
dependent functions on a graph. We usually take for granted that the independent variable in the $x$-axis represents time. In fact, there is an automatic activation of the analogy that maps times and locations in space, which allows us to visualize and correctly interpret the graph. Students are expected to conceptualize time in terms of the Time's Landscape metaphor because this makes up the intuitive basis for representing time-dependent functions. By simply superimposing the signals of Fig. 3 into a unique sinewave, time is converted into the $x$-axis variable. After years of schooling, most students have usually internalized the interpretation of time-dependent functions as represented on the Cartesian plane. This is obviously the case of Western students who learned to write from left to right, and straightforwardly interpret time graphs in the writing direction. Other linguistic groups write in a different manner (direction) as Chinese (from top to down) or Arabic and Hebrew speakers (from right to left) do. These writing conventions effectively shape people's representations of time (Fuhrman et al. 2011). Despite this variability scientific graphs follow the Western convention.

One would even speculate that Time's Landscape metaphor lies behind a culturally favored conceptualization of time used in modern science and engineering. Recalling historical accounts, it is known that geometrical representations of time-dependent functions can be encountered in the works of medieval thinkers. For instance, in the XIVth century Nicole Oresme's schema first represented time as a horizontal line, whereas the intensity of any quality was drawn as a vertical line (Lindberg 1992). Thereby the representation of motions could be visualized in terms of a geometrical shape. However, the spread of this space-time mapping activation took some centuries. Later in the eighteenth century, only scientists and engineers were able to interpret and use time graphs. So the chemist Joseph Priestley (17331804) felt obliged to explain his use of time graphs by this fashion (Headrick 2000): "Thus the abstract idea of time... admits of a natural and easy representation in our minds by the idea of a measurable space, and particularly that of a line; which like time may be extended in length, 
without giving any idea of breadth of thickness. And thus a longer or a shorter space of time may be most commodiously and advantageously represented by a longer or a shorter line." Therefore time, in being conceptualized by means of spatial notions within the Time Landscape metaphor could be quantified so as to form part of the development of the visual features of modern technology (Crosby 1997). This particular time metaphor was assimilated into the scientific cultural tradition and finally incorporated into electronic displaying instruments.

The historian Peter Burke introduced the term 'cultural tradition' in the sense used here (Burke 1978). From an anthropological point of view, a culture is seen as a structure of shared meanings that can be understood by the people immersed in it, and confers order and sense to the reality (Geertz 1973). Cultures are always historical constructs that evolve, interact and change continuously (Sahlins 1985). The force behind this evolution is in fact the people's practices and daily negotiations confronting meanings and interpretations (Sewell 1999). Cultural practices comprise every activity by means of which meanings are not only maintained and supported, but also reoriented and hybridized. This concept of culture is elastic enough to allow speaking of different cultures or subcultures within a given society, in such a way that it is conceivable thinking about popular and elite cultures, or also scientific and mass cultures. Each one presenting its own history, expressions and external exchanges, and giving rise to conflicts, collisions, borrows, and fruitful influences in relation to other cultures (Burke 2009). Scientific culture then gathers its own shared meanings and concepts technologically embodied in instruments as occurs with the oscilloscope presented here. Obviously there is not a unique scientific culture as pointed out convincingly in previous studies (Galison 1997). Peter L. Galison studied the material culture (instrumentation) of two closely related branches of the particle physics. He observed how the traditions of these two subcultures were evolving in parallel with relatively poor cross-fertilization. 
It is interesting to note here that the opposite metaphor (Moving Time) was essential in the development of other cultural traditions. During the XIXth century the combination of popular culture and new projection systems gave rise to the birth of cinema, one of the expressions of the current mass culture. Also educated within this tradition students of different linguistic groups around the world are used to seeing a screen on which dynamic events occur while the observer occupies a stable position.

It should be recognized that cinema has developed a variety of ways for managing time during the last century. This obviously configures a specialized notion commonly known as cinematographic time that may exhibit different and certainly sophisticated structures. Filmmakers have invented a variety of procedures to manage time: simultaneity, flash-back, subjective views... and scholars distinguish a break point in the 1960-70s that impelled cinema to freely manipulate and alter time in unfamiliar fashions. I am however interested here in the simplest version of cinema: a short single shot filmed by a still camera, as a contrasting example of an apparatus conceived and devised to show change and motion instead of stillness. In opposition to the stopped image of a time-varying, dynamic event provided by the oscilloscope, cinema screens highlights the moving features of the things as displayed in simple shots. Interestingly, cinema scholars (Doane 2002) realized that the filmic process creates an illusion of movement from static images. As Doane claims, "[t]he cinema attempts to reconstitute movement with a series of still photographs, but none of these photographs has anything to do with movement. Their gestures are static, frozen". And also "[t]he moment of fascination in the early cinema is the moment when the still image projected on the screen bursts into movement". It seems therefore that the two displaying technologies (oscilloscopes and films) seek for completely opposite purposes: whereas oscilloscopes intend to show static views of changing phenomena, cinema cameras and projectors embody a procedure to recreate motion from stillness. This last observation about the hidden mechanism 
behind the reconstruction of motion from a set of filmed photograms resembles the original view of the Moving Time metaphor. In the metaphor there is a succession of objects (time) that move from front to back the observer. Similarly a film strip is a sequence of frozen images that passes through the optical system of the projector and thereby creates movement. It is then important to stress how different technological cultural traditions incorporate time views according to their effectiveness in terms of particular recognition abilities.

As previously explained, the conceptual mapping described constitutes the central part of our commonsense understanding about time and time-related events. However, it should be noticed that such an analogic schema does not form a coherent and consistent whole. The activation of either the Time Landscape metaphor or the Moving Time metaphor mainly depends on the actual situation and its particular details. Depending upon whether the activity is understood as belonging to one specific cultural practice or another, then specific visualization forms should be activated.

\section{Changing Views in a Thought Experiment}

The experiences described with the oscilloscope images point to a failure in the students' understanding as a result of the fact that they see the instrument as fixed, lying on the lab bench, and try to think about the signal as passing over. As commented previously a dynamic sinewave is sometimes observed resembling the motion on a cinema screen. One can imagine that students are just trying to apply the Moving Time metaphor (process 1), which seems to naturally match the experiment situation: the observer (the oscilloscope) is stationary at a given spatial location and the time-dependent signal is conceived as moving towards it. Explaining frameworks of this sort are commonly drawn when teachers introduce students in the subject of signal transmission and communication systems. Emitter and receiver are always represented at a fixed position while a moving signal accompanies the textbook 
drawings. This kind of conceptualization might block the students' thought, and limits proper understanding. I suggest here that in order to catch the wave in the laboratory, most students will have to change their conceptual schema and think of using another viewpoint.

This change in the conceptual view entails a movement of students' thought able to make explicit the type of linguistic modes they implicitly have in mind to conceptualize time. Students are suggested to imagine the signal as having stopped, as they usually do in drawing time-dependent functions, and allow the oscilloscope (the observer) to run along the signal track (process 2). This is in fact a change in the spatial time analogies from the Moving Time metaphor to the Time Landscape metaphor. One can imagine replicas of the oscilloscope screen superimposed to the sinewave at different times starting at the same oscillation point. The signal that appears on the oscilloscope screen will be a frozen sinewave only in those cases in which the space of time (interval) between successive recordings is constant. This is of course what the trigger system of the apparatus actually does.

Once a stable signal is on the screen (second image in Fig. 1), it is feasible for students to measure, for instance, the period of the sinewave as if it were a time-dependent function representation. Therefore, the instrument delivers a representation of the signal ready to be interpreted in the useful framework of the Time Landscape metaphor (process 3). In this last step the student becomes the observer and can easily displace her/his finger along the signal trace. In the modern oscilloscope digital versions, the screen cursors operated by the oscilloscope user make the measurement. We see therefore that the dual conceptualization of time can be applied or activated at different levels depending on the current experimental situation, be it real or thought. More importantly students gain a deeper comprehension about the instrument operation if instruction makes explicit use of the metaphorical mapping. 


\begin{tabular}{|c|c|c|c|}
\hline & Observer & $\begin{array}{l}\text { Time } \\
\text { concept }\end{array}$ & \\
\hline Process 1 & Instrument & $\begin{array}{l}\text { Moving } \\
\text { Time }\end{array}$ & $\begin{array}{l}\text { Moving traces observed on the } \\
\text { oscilloscope screen. It blocks proper } \\
\text { interpretation of time-varying signal. }\end{array}$ \\
\hline Process 2 & Instrument & $\begin{array}{l}\text { Time's } \\
\text { Landscape }\end{array}$ & $\begin{array}{l}\text { Explanation of the synchronization } \\
\text { process as performed by the trigger } \\
\text { setting. It allows seeing time-varying } \\
\text { signals as represented by replicas of } \\
\text { similar images. }\end{array}$ \\
\hline Process 3 & Student & $\begin{array}{l}\text { Time's } \\
\text { Landscape }\end{array}$ & $\begin{array}{l}\text { Static visualization of traces. It allows } \\
\text { quantification in } x-y \text { plots and proper } \\
\text { measurement. }\end{array}$ \\
\hline
\end{tabular}

Table 1. Sequence of movements involved in the interpretation of instrument-mediated signals

It should be stressed that the key point to correctly 'read' the incoming signal consists in synchronizing the oscilloscope time-base and the sinewave period. The apparatus trigger needs to be adjusted to allow students to 'stop' the signal. We can see, therefore, that before the instrument provides a readable drawing, some kind of apparatus manipulation is necessary to remove false outcomes. People experienced in manipulating oscilloscopes or other types of displaying instruments, usually take all the previous tunings for granted. When the instrument is properly triggered, a stable visual representation of the signal appears on the screen. The instrument might be then regarded as a black box. The activation of the Time Landscape 
metaphor (process 3) is then rather straightforward and needs no further explanation. However during the training process of gaining expertise, the type of visualization needed for image interpretation is not yet internalized. This is the case of science and engineering students who are being introduced into elementary laboratory practices, particularly if instruments displaying images and graphs are being employed.

\section{Role of instruments as mediators}

From an ethnographic perspective education and instruction can be assimilated to a process of acculturation in which students progressively adapt to or borrow traits from the scientific culture. This view emphasizes the contrast between common, external (to the education institution) ways of interpreting physical phenomena, and internal approaches connected to the scientific practices and concepts. External and internal practices belong in principle to different cultures, let us say contemporary Western and scientific cultures in my teaching experience. However practices occurring outside the school become of primary concern to understand students' conceptions and ideas that constitute the starting point for the development of academic knowledge (Hammer 1996). Relying on previous work (Nespor 1994, 2004) more recently Antonia Candela provided an ethnographic account on the students' trajectories as spatially and temporally distributed events institutionally organized as obligatory passage points on the route to stabilize the identity as scientists or engineers (Candela 2010). Recalling our previous accounts on cultural traditions, classrooms can be then seen as privileged locations for cultural hydridation (Burke 2009). Teachers and students are involved in a work that continuously relates classroom activities to outside practices, experiences and conceptualizations. Hence instruction should always take into account other settings, moments and meanings in a sort of cross-cultural negotiation. It should be stressed that learning instrumental (relative to the instruments) knowledge is per se a practical task so 
that the cross-cultural negotiation aims at configuring a community of practices that foster a collective refinement of the visual display interpretation.

Here I have identified two ways of understanding time as used in different trajectories through which students are located. Interestingly specific displaying instruments belonging to different cultural traditions incorporate contrasting time views. One of them sees time in terms of a dynamic metaphor consisting of a static observer looking at passing events. As introduced previously, this is a general and widespread practice common in the contemporary mass culture, which lies behind the process of making sense to moving images usually visualized by means of movie shots. In contrast scientific culture favored another way of time conceptualization (static time metaphor) that historically fostered the construction of graphs and the incorporation of time-dependent functions as represented on the Cartesian plane into displaying instruments. Both types of cultures, scientific and mass, are considered highly technological in the sense that complex instruments, apparatus or machines participate in their visual practices. Displaying instruments as oscilloscopes or cinema projectors can be thought as cultural artifacts (Schiffer 1999) involved in the production and communication of shared meanings, and devised for specific functions (Graves-Brown 2000). The identification of these two time views and their common uses and practices embodied in artifacts would allow teachers to guide students during the instructional approach to displaying instruments. But why instruments are so important in training future scientists? As next explained instruments constitute core participants of the scientific practices.

Bruno Latour first identified the crucial role instruments play as "inscription devices" able to produce scientific graphs (Latour and Woolgar 1986). He defined instruments as "any setup, no matter its size, nature and cost, that provide a visual display of any sort in a scientific text". Graphical displays of data become central rather than peripheral in the process of constructing and communicating scientific knowledge (Latour 1990). Graphs are involved in 
crucial discursive practices for enrolling allies to a particular, not fully established points of view, and for persuading other scientists on the value of one's research (Latour 1987). Following the Latour's approach instruments can be viewed as bottle necks of obligatory pass that condense previous knowledge after closing former controversies in a particular scientific field. It is then understandable that students' training trajectories should pass through them.

I finish by emphasizing the role played by the recording instruments (the oscilloscope in this case). As Don Idhe pointed out, an intrinsic relationship exists between visualization ways and the use of scientific instrumentation (Idhe 1991). The basis of such visualization in science and engineering relies on ordinary perception. However, visualization is possible by means of the instrument mediation, which makes signals readable. The instrument then is devised to transform the information and display it in such a way that matches the specific mode of perception of the outer observer. The graph generated is then ready to be used for measuring any physical variable, or as a rhetorical inscription within a scientific text.

\section{Concluding remarks}

The linguistic perspective introduced explains how there are sound accounts that analyze thought and reasoning in terms of low-level ideas. These conceptual structures manifest themselves as conventional linguistic patterns. Time is conceived in everyday talk in terms of spatial (visual) notions by means of two different analogies or metaphors. The explicit knowledge of students' conventional conceptions of time can improve their understanding of signal recording, and contribute to form a solid base on which to build further science and engineering concepts and fruitful laboratory practices. The analysis reported here highlights the interplay between visualization and imaging interpretation in order to make sense of the oscilloscope graphs, and achieve a proper reading. The linguistic account, when explicitly stated to students, becomes fruitful and firmly tied to thinking processes through visualization 
mechanisms.

\section{Acknowledgment}

I would like to acknowledge Dr. F. X. Garcia Belmonte for fruitful discussions on the cultural tradition concept, and its relation to scientific practices.

\section{References}

Bell, L., Juersivich, N., Hammond, T. C., \& Bell, R. L. (2012). The TPACK of dynamic representations In R. N. Ronau, C. R. Rakes \& M. L. Niess (Eds.), Educational Technology, Teacher Knowledge, and Classroom Impact: A Research Handbook on Frameworks and Approaches. Hershay, PA: IGI Global.

Boroditsky, L. (2000). Metaphoric structuring: understanding time through spatial metaphors. Cognition, 75, 1-28.

Boroditsky, L. (2001). Does Language Shape Thought?: Mandarin and English Speakers' Conceptions of Time. Cognitive Psychology, 43, 1-22.

Burke, P. (1978). Popular Culture in Early Modern Europe Surrey: Ashgate Publishing Limited.

Burke, P. (2009). Cultural Hybridity. Cambridge: Polity Press.

Candela, A. (2010). Time and space: undergraduate Mexican physics in motion. Cultural Studies of Science Education, 5, 701-727.

Clark, J. M., \& Paivio, A. (1991). Dual Coding Theory and Education. Educational Psychology Review, 3, 149-170.

Contero, M., Naya, F., Company, P., Saorín, J. L., \& Conesa, J. (2005). Improving visualization skills in engineering education. IEEE Computer Graphics and Applications, September/October, 24-31.

Crosby, A. W. (1997). The Measure of Reality: Quantification and Western Society, 12501600. Cambridge: Cambridge University Press.

Dias Pereira, J. M. (2006). The history and technology of oscilloscopes: An overview of its primary characteristics and working principles. IEEE Instrumentation \& Measurement Magazine, December, 27-35.

Doane, M. A. (2002). The Emergence of the Cinematic Time: Modernity, Contingency, the Arichive Cambirdge: Harvard University Press

Fuhrman, O., McCormick, K., Chen, E., Jiang, H., Shu, D., Mao, S., \& Boroditsky, L. (2011). How Linguistic and Cultural Forces Shape Conceptions of Time: English and 
Mandarin Time in 3D. Cognitive Science, 35, 1305-1328.

Gale, R. (1968). The Language of Time. London: Routledge.

Gale, R. (Ed.). (1967). The Philosphy of Time. New York: Doubleday.

Galison, P. (1997). Image and Logic: a Material Culture of Microphysics Chicago: The Chicago University Press.

Geertz, C. (1973). The Interpretation of Cultures: Selected Essays New York: Basic Books. Gell, A. (1992). The Antrhopology of Time. Providence: Berg Publishers Ltd.

Gentner, D., Imai, M., \& Boroditsky, L. (2002). As time goes by: Evidence for two systems in processing space-time metaphors. Language and Cognitive Processes, 17(5), 537-565.

Giaquinto, M. (2007). Visual Thinking in Mathematics: An Epistemology Study. Oxford: Oxford University Press.

Gilbert, J. K. (2007a). Visualization: a metacognitive skill in science and science education. In J. K. Gilbert (Ed.), Visualization in Science Education Dordrecht: Springer.

Gilbert, J. K. (Ed.). (2007b). Visualization in Science Education. Dordrecht: Springer.

Gilbert, J. K., Reiner, M., \& Nakhleh, M. (Eds.). (2008). Visualization: Theory and Practice in Science Education (Vol. 3): Springer.

Granet, M. (1968). Le Temps et l'Espace. In La pensee Chinoise. Paris: Albin Michel.

Graves-Brown (Ed.). (2000). Matter, Materiality and Modern Culture. London: Routledge.

Hammer, D. (1996). More than misconceptions: Multiple perspective in student knowledge and reasoning, and an appropiate role for education research. American Journal of Physics, 64, 1316-1325.

Headrick, D. N. (2000). When Information Come of Age: Technologies of Knowledge in the Age of Reason and Revolution, 1700-1850. Oxford: Oxford University Press.

Idhe, D. (1991). Instrumental Realism. The Interface between Philosophy of Science and Philosophy of Technology. Bloomington: Indiana University Press.

Lakoff, G., \& Johnson, M. (1980). Metaphors We Live by. Chicago: The University of Chicago Press.

Lakoff, G., \& Johnson, M. (1999). Philosophy in the Flesh. New York: Basic Books.

Latour, B. (1987). Science in Action. Cambridge: Harvard University Press.

Latour, B. (1990). Drawing things together. In M. Lynch \& S. Woolgar (Eds.), Representation in Scientific Practice (pp. 19-68). Cambridge, MA: MIT Press.

Latour, B., \& Woolgar, S. (1986). Laboratory Life: The Construction of Scientific Facts Princeton: Princeton University Press.

Lindberg, D. C. (1992). The Beginnings of the Western Science. The European Scientific 
Tradition in Philosophical, Religious, and Institutional Context, 600 B.C. to 1450. Chicago: The University of Chigaco Press.

Lowe, R. K., \& Schnotz, W. (Eds.). (2007). Learning with Animation: Research Implications for Design. New York: Cambridge University Press.

McKagan, S. B., Perkins, K. K., Dubson, M., Malley, C., Reid, S., LeMaster, R., \& Wieman, C. E. (2008). Developing and researching PhET simulations for teaching quantum mechanics. American Journal of Physics, 76, 406-417.

Munn, N. D. (1992). The Cultural Anthropology of Time: A Critical Essay. Annual Review of Anthropology, 21, 93-123.

Nespor, J. (1994). Knowledge in Motion: Space, Time and Curriculum in Undergraduate Physics and Management. London, New York: Routledge Farmer.

Nespor, J. (2004). Educational scale-making. Pedagogy, Culture and Society, 12, 309-326.

Núñez, R. E., \& Sweetser, E. (2006). With the Future Behind Them: Convergent Evidence From Aymara Language and Gesture in the Crosslinguistic Comparison of Spatial Construals of Time. Cognitive Science, 30, 401-450.

Phillips, L. M., Norris, S. P., \& Macnab, J. S. (2010). Visualization in Mathematics, Reading and Science Education. Dordrecht: Springer.

Rapp, D. N. (2007). Mentals models: Theoretical issues for visualizations in science education. In J. K. Gilbert (Ed.), Visualization in Science Education. Dordrecht: Springer.

Rapp, D. N., \& Kurby, C. A. (2008). The 'ins' and 'outs' of learning: Internal representations and external visualizations In J. K. Gilbert, M. Reiner \& M. Nakhleh (Eds.), Visualization: Theory and Practice in Science Education: Springer.

Roth, W.-M., Pozzer-Ardenghi, L., \& Han, J. Y. (2005). Critical Graphicacy: Understanding Visual Representation Practices in School Science Springer.

Sahlins, M. (1985). Islands of History. Chicago: University of Chicago Press.

Schiffer, M. B. (1999). The Material Life of Human Beings. London: Routledge.

Sewell, J., W. H. (1999). The concept(s) of Culture. In V. E. Bonnell \& L. Hunt (Eds.), Beyond the Cultural Turn. New Directions in the Study of Society and Culture (pp. 35-61). Los Angeles: University of California Press.

Torralbo, A., Santiago, J., \& Lupiáñez, J. (2006). Flexible Conceptual Projection of Time Onto Spatial Frames of Reference. Cognitive Science, 30, 745-757.

Tversky, B., Morrison, J. B., \& Betrancourt, M. (2002). Animation: Can it facilitate? . International Journal of Human Computer Systems 57, 247-262.

Wu, H. K., \& Shah, P. (2004). Exploring visuospatial thinking in chemistry learning. 
Science Education, 88, 465-492.

\section{Biographical information}

Germà Garcia-Belmonte is currently a full professor in Applied Physics at Universitat Jaume I in Castelló, Spain. He has published several papers of educational focus in Physics and Engineering. Since 1993 he has been a full time teacher in various subjects of Physics (Electromagnetism, Optics, Thermodynamics, and Acoustics) and Electronics (Instrumentation, Signal Processing, Sensors) in Engineering courses (Electrical, Electronics, Computer, Technical Design, Mechanical). He has also prepared laboratory courses and educational experiments. Some of these experiments were published in journals such as IEEE Transactions on Education, and American Journal of Physics. 